\title{
VanWyk-Grumbach syndrome in a male pediatric patient: A rare case report and literature review
}

\author{
SHANSHAN ZHANG, JINGYAN YANG, RONGXIU ZHENG, LIHONG JIANG, YING WEI and GELI LIU \\ Department of Pediatrics, General Hospital of Tianjin Medical University, Tianjin 300052, P.R. China
}

Received November 22, 2015; Accepted November 25, 2016

DOI: $10.3892 /$ etm.2017.4086

\begin{abstract}
Primary hypothyroidism usually leads to retardation of linear growth and delay or even arrest of puberty in juvenile patients. In rare cases, pediatric patients with hypothyroidism may present with signs of VanWyk-Grumbach's syndrome (VWGS), which includes juvenile hypothyroidism, delayed bone age and pseudoprecocious puberty. The present study reported on a rare case of VWGS and other complications, including obesity, short stature, hepatomegaly and pituitary hyperplasia. In addition, a comprehensive literature review was performed to illustrate the treatment and outcome of VWGS in pediatric patients. The present study contributed to the current knowledge regarding the diagnosis and treatment of VWGS in pediatric patients.
\end{abstract}

\section{Introduction}

VanWyk-Grumbach syndrome (VWGS) is characterized by delayed bone age, juvenile hypothyroidism and isosexual precocious puberty (1). VWGS patients usually show decreased free thyroxine (T4), together with elevated prolactin, estradiol and thyroid-stimulating hormone (TSH). At present, VWGS is well acknowledged as a prepubertal response mediated by follicle-stimulating hormone (FSH). Besides, the expression of luteinizing hormone (LH) is suppressed as revealed by the elevation of LH-releasing hormone (LHRH). All of these results confirmed that VWGS is a gonadotropin-releasing hormone (GnRH)-independent type of precocious pseudopuberty (2-9).

Phenotypically, female patients with VWGS show breast enlargement, early onset of menstrual bleeding and enlarged multicystic ovaries. In male patients, the only symptom is testicular enlargement without substantial Leydig cell stimulation or testosterone secretion (5). To the best of our knowledge, the incidence of VWGS has been more commonly reported in females $(3,4,10,11)$, with very few case studies on males $(9,12)$. The present case report presented a boy with features of

Correspondence to: Professor Geli Liu, Department of Pediatrics, General Hospital of Tianjin Medical University, 154 Anshan Road, Tianjin 300052, P.R. China

E-mail: liugeli008@sina.com

Key words: hypothyroidism, VanWyk-Grumbach syndrome
VWGS and described the pathophysiology, clinical manifestation and treatment. Furthermore, a literature review was performed regarding the treatment of VWGS in male patients and its outcome.

\section{Case report}

A 14-year-old male patient of non-consanguineous parents was referred to the Department of Pediatrics of the General Hospital of Tianjin Medical University (Tianjin, China) due to obesity, short stature and muscle weakness in February, 2014. He had shown progressive weight gain, delay in growth, constipation, muscle weakness and poor academic scores over the past 3-4 years. Physical examination results were as follows: Body temperature, $36.5^{\circ} \mathrm{C}$; heart rate, 60 beats per min; respiratory rate, 20/min; blood pressure, 100/70 $\mathrm{mmHg}$; body weight, $59 \mathrm{~kg}$ ( $>97$ th percentile); height, $139 \mathrm{~cm}$ (<3rd percentile); and body mass index, 30.5 ( $>97$ th percentile). The thyroid gland was enlarged. Abdominal examination indicated hepatomegaly and cardiac examination indicated a slightly distant heart sound without murmurs. The bilateral testicular volume was $25 \mathrm{ml}$ as measured by a Prader orchidometer (Creative Health Products, Ann Arbor, MI, USA) and stretched penile length was $5 \mathrm{~cm}$. No pubic or axillary hair was observed. Laboratory results are summarized in Table I. Laboratory parameters associated with renal function were normal. Thyromegaly accompanied with low-intensity echoes were identified by thyroid ultrasound. Abdominal ultrasound revealed hepatomegaly. Delayed bone age was confirmed according to X-ray imaging of the left wrist and hand (Fig. 1) with an estimated bone age of 10 years. Cranial magnetic resonance imaging (MRI) indicated enlargement of the pituitary gland (Fig. 2), and pituitary hyperplasia was suspected. Based on these results, the patient was finally diagnosed as VWGS. As a treatment, replacement therapy was given using levothyroxine with an initial dose of $25 \mu \mathrm{g} / \mathrm{m}^{2} /$ day, which was gradually increased to $100 \mu \mathrm{g} / \mathrm{m}^{2} /$ day. The patient was followed up for 6 months and the levels of free triiodothyronine (T3), T4 and TSH were $4.35 \mathrm{pmol} / 1,18.65 \mathrm{pmol} / 1$ and $3.31 \mu \mathrm{IU} / \mathrm{ml}$, respectively. The body height showed an increase of $5 \mathrm{~cm}$ after the treatment.

\section{Discussion}

Primary hypothyroidism has been well acknowledged to be associated with growth and pubertal delay. In rare cases, 
Table I. Laboratory results of the patient.

\begin{tabular}{lcc}
\hline Parameter & Value & $\begin{array}{c}\text { Normal } \\
\text { range }\end{array}$ \\
\hline Hemoglobin, g/l & 87 & $120-150$ \\
Thyroid-stimulating hormone, & $>150$ & $0.3-5$ \\
$\mu \mathrm{IU} / \mathrm{ml}$ & & \\
T3, pmol/l & 1.19 & $3.5-6.5$ \\
Free thyroxine, pmol/l & 4.78 & $11.5-23.5$ \\
Thyroglobulin antibody, IU/ml & 164 & $0-40$ \\
Anti-thyroidperoxidase antibody, & $>1,000$ & $0-35$ \\
IU/ml & & \\
Antibodies against TSH receptor, & 0.01 & $0-1.5$ \\
IU/ml & & \\
Follicle-stimulating hormone, IU/ml & 26.7 & $1.4-18 \mathrm{I}$ \\
Luteinizing hormone, IU/ml & 0.37 & $1.5-34.6$ \\
Progesterone, ng/ml & $<0.15$ & $0.28-1.22$ \\
Estradiol, pg/ml & 12.11 & $0-40$ \\
Prolactin, pg/ml & 21.94 & $2.1-17.7$ \\
Testosterone, ng/dl & 72.5 & $241-827$ \\
Adrenocorticotropic hormone, pg/ml & 23.6 & $0-46$ \\
Serum cortisol, $\mu \mathrm{g} / \mathrm{dl}$ & 11.5 & $5-25$ \\
Cholesterol, mmol/l & 12.17 & $<5.20$ \\
Triglyceride, mmol/l & 1.12 & $0.56-1.70$ \\
Alanine aminotransferase, $\mathrm{U} / \mathrm{l}$ & 87 & $5-40$ \\
Aspartate aminotransferase, U/l & 82 & $8-40$ \\
Alkaline phosphatase, U/l & 122 & $40-150$ \\
\hline
\end{tabular}

hypothyroidism was reported to induce precocious puberty and delayed bone age. These symptoms were initially described in 1905; however, VWGS was only defined in 1960 (1). A literature review revealed that VWGS has been rarely reported in male patients $(13,14)$. The present study presented a rare case of a male pediatric patient with VWGS.

The pathogenesis of VWGS is closely associated with the complex interactions between the hypothalamic-pituitary axis. Van Wyk and Grumbach postulated that a hormonal overlap occurred in the pituitary feedback mechanism. Given that gonadotropins as well as TSH are glycoproteins, their overlap at the hormonal level is partly associated with the lack of specificity at the hypothalamic level (1). Moreover, excess TSH induced by thyrotropin-releasing hormone (TRH) may act as an agonist of FSH receptor (FSH-R) and other $\mathrm{G}$ protein-coupled receptors (GPCRs). In the peripubertal phase, where FSH levels are low, FSH-R is more apt to be stimulated by TSH $(2,15,16)$. In addition, FSH-R responds to TSH in a dose-dependent manner $(15,16)$. Furthermore, human chorionic gonadotropin (hHCG), LH, FSH and TSH share the same $\alpha$-subunit, while a unique $\beta$-subunit specific to each hormone was identified. These molecules activate adenylate cyclase and stimulate cyclic adenosine monophosphate (cAMP) production by interacting with GPCRs (17).

In a previous study, Anasti et al (15) indicated that recombinant human TSH elicited a dose-dependent cAMP response in an in vitro hFSH-R bioassay. However, the concentration

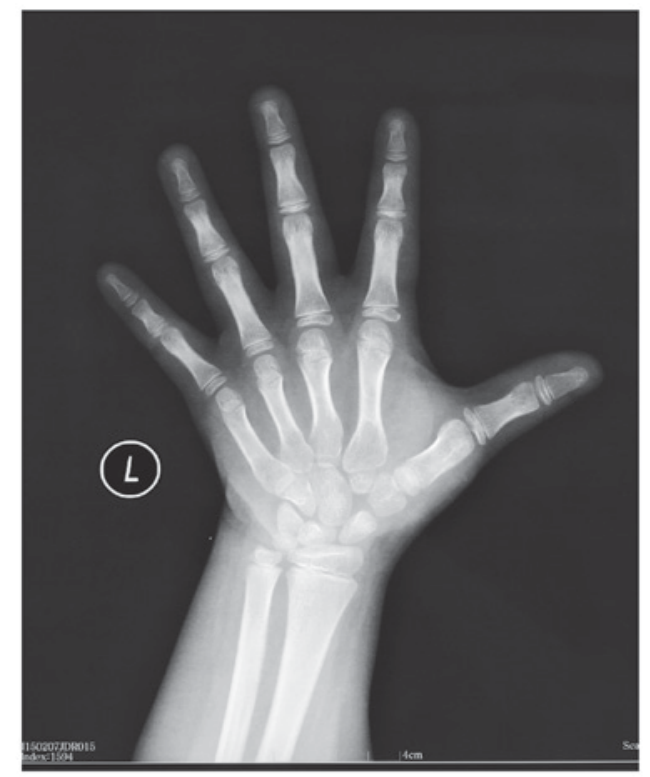

Figure 1. X-ray indicated delayed bone age in left wrist compared with the actual age (10 vs. 14 years).

of recombinant hTSH required for half-maximal stimulation was several $\log$ g greater than that of hFSH. These results suggested that hTSH and hFSH act through the same receptor. The overlap between the glycoprotein hormones is not unprecedented in the presence of excessive secretion of hormones. For instance, with the homologous $\beta$-subunits of $\mathrm{LH}, \mathrm{HCG}$ is able to stimulate $\mathrm{LH}$ receptors and serve as an evaluation method for testicular function in male pediatric patients through determination of the binding of HCG and $\mathrm{LH}$ receptor. To investigate the exact activation of $\mathrm{TSH}$ on FSH-R, Ryan et al (16) sequenced the FSH-R gene in 8 patients with overexpression of sex hormone secondary to primary hypothyroidism, which revealed no hFSH-R mutations in the patient population; however, two known polymorphisms were identified. Besides, the gonadal hyperstimulation associated with severe primary hypothyroidism is likely due to the actions of the elevated concentrations of TSH on the wild-type hFSHR, which is not dependent on the hFSH-R isoform (18).

Severe hypothyroidism is one of the major causes for the changes of gonadotrophins, such as elevation of FSH or decrease of LH $(19,20)$. In primary hypothyroidism patients, the level of TRH was elevated, which resulted in a decrease of pulse frequency of $\mathrm{GnRH}$ and the downregulation of GnRH secretion (21-23). Under these conditions, the expression of FSH was elevated and the elevation of TRH induced hyperprolactinemia, which induced a decrease of LH (24). Such aspects may explain for the discordance between $\mathrm{LH}$ and FSH in VWGS. In a previous study, Francavilla et al (25) indicated that hypothyroidism directly affected the function of testis prior to puberty, resulting in excess proliferation of Sertoli cells and testicle enlargement. Male patients with VWGS have macroorchidism without obvious virilisation, and testicular histology reveals a predominance of tubular structures without increased Leydig cells, in line with an FSH-dominated response $(15,26)$. However, enlargement of gonads and formation of ovarian cysts are usually 
A

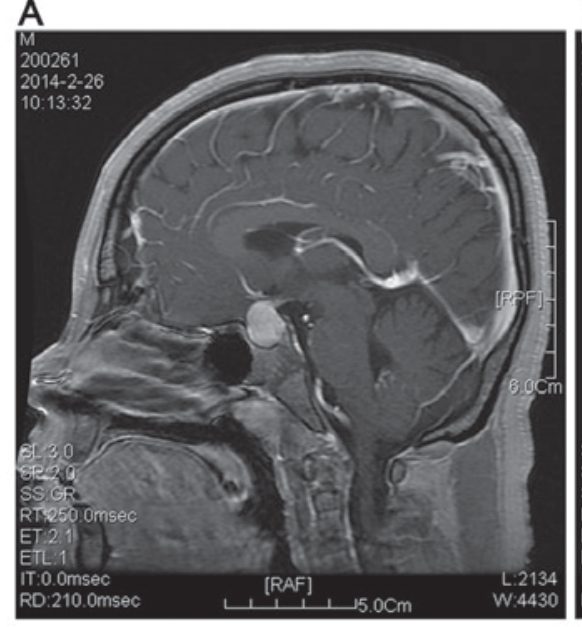

B

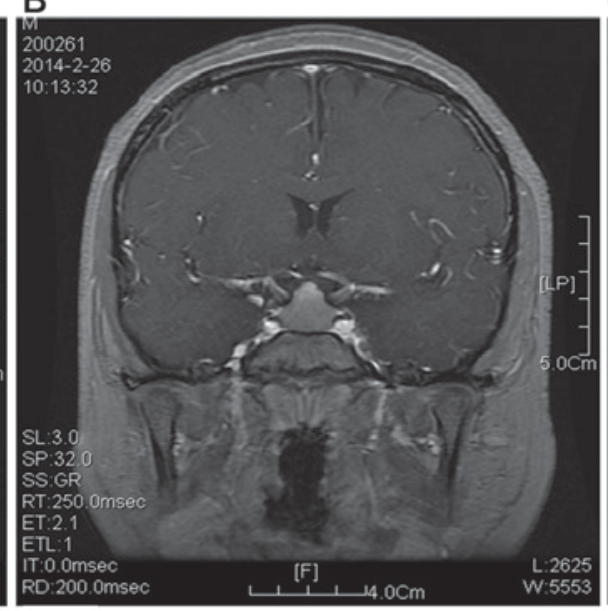

C

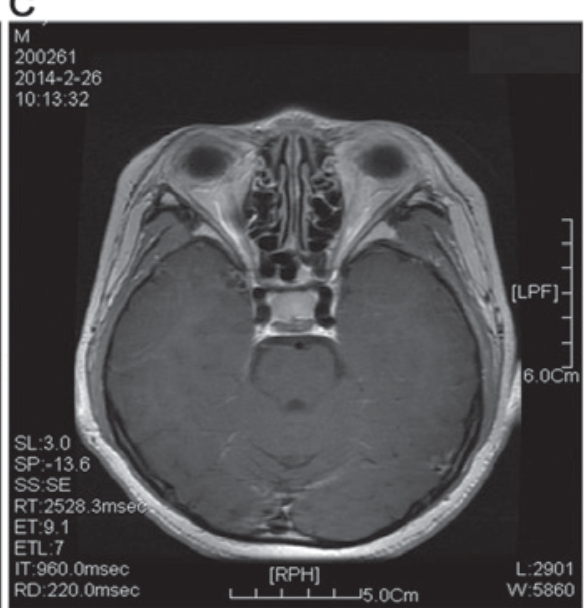

Figure 2. Pituitary magnetic resonance image indicating enlargement of the pituitary gland, and pituitary hyperplasia was suspected based on the (A) sagittal, (B) coronal; and (C) transverse views.

associated with malignant conditions $(3,4,27)$. Thus, early diagnosis of the disease may help to identify cases that require surgery $(5,6)$.

Weight gain has been regarded as a symptom of hypothyroidism. In the complete absence of thyroid hormone, basal metabolic rate or resting energy expenditure was reduced by $30 \%$ or even $59 \%$ (28). In the present case, the patient showed elevation of cholesterol liver enzymes and hepatomegaly, which may be associated with hypercholesterolemia induced by hypothyroidism. Besides, hypothyroidism has been reported to have an important role in the pathogenesis of nonalcoholic fatty liver disease (NAFLD) (29). Specifically, Chung et al (30) reported that NAFLD was more severe and liver enzyme was significantly elevated in patients with hypothyroidism compared to those in normal subjects. In the present case, pituitary enlargement was revealed by cranial MRI, which may result in long-term hypothyroidism. In addition, the thyrotroph hyperplasia may lead to sella turcica expansion and pituitary hyperplasia.

Certain uncommon features, including PTH suppression, streaky hyperpigmentation and severe anemia, have been reported in certain patients (10). It has been well acknowledged that melanocyte stimulating hormone (MSH) may be involved in the pigmentation of local skin tissues (1). As MSH acts via GPCRs, it is reasonable to speculate that streaky hyperpigmentation may be induced by differences in receptor distribution and activities in the presence of homologies and cross reaction between MSH and TSH. In the present case, the patient presented with anemia, which is, to the best of our knowledge, not common in hypothyroidism (31), while it has been noted in certain cases of VWGS $(2-5,7,32)$. It was speculated that the anemia may be associated with the reduced red cells and decreased metabolic oxygen requirement in tissues of patients with hypothyroidism (31).

In conclusion, the pathogenesis of VWGS involves a complex interaction, which is, at least in part, directly mediated by FSH and TSH receptors. It is suggested that the 'overlap' of hormone actions, postulated by Van Wyk and Grumbach (1), may be reflected in receptor levels. In particular, all hormones involved may act through GPCRs and common intracellular signaling pathways in the presence of elevated TSH. Early diagnosis and thyroxine replacement therapy are recommended for the treatment of VWGS.

\section{References}

1. Van Wyk JJ and Grumbach MM: Syndrome of precocious menstruation and galactorrhea in juvenile hypothyroidism: An example of hormonal overlap in pituitary feedback. J Pediatrics 57: 416-435, 1960

2. Shu J, Xing L, Zhang L, Fang S and Huang H: Ignored adult primary hypothyroidism presenting chiefly with persistent ovarian cysts: A need for increased awareness. Reprod Biol Endocrinol 9: 119, 2011.

3. Browne LP, Boswell HB, Crotty EJ, O'Hara SM, Birkemeier KL and Guillerman RP: Van Wyk and Grumbach syndrome revisited: Imaging and clinical findings in pre-and postpubertal girls. Pediatr Radiol 38: 538-542, 2008.

4. Panico A, Lupoli GA, Fonderico F, Colarusso S, Marciello F, Poggiano MR, Del Prete M, Magliulo R, Iervolino P and Lupoli G: Multiple ovarian cysts in a young girl with severe hypothyroidism. Thyroid 17: 1289-1293, 2007.

5. Indumathi $\mathrm{C}$, Bantwal $\mathrm{G}$ and Patil $\mathrm{M}$ : Primary hypothyroidism with precocious puberty and bilateral cystic ovaries. Indian J Pediatr 74: 781-783, 2007.

6. Chattopadhyay A, Kumar V and Marulaiah M: Polycystic ovaries, precocious puberty and acquired hypothyroidism: The Van Wyk and Grumbach syndrome. J Pediatr Surg 38: 1390-1392, 2003.

7. Ozgen T, Güven A and Aydin M: Precocious puberty in a girl with Down syndrome due to primary hypothyroidism. Turk $\mathrm{J}$ Pediatr 51: 381-383, 2009.

8. Zhang H, Geng N, Wang Y, Tian W and Xue F: Van Wyk and Grumbach syndrome: Two case reports and review of the published work. J Obstet Gynaecol Res 40: 607-610, 2014.

9. Esen I and Demirel F: Hypothyroidism-associated testicular enlargement: Is it a form of precocious puberty or not? A case report. Turk J Pediatr 53: 210-212, 2011.

10. Baranowski E and Högler W: An unusual presentation of acquired hypothyroidism: The Van Wyk-Grumbach syndrome. Eur J Endocrinol 166: 537-542, 2012.

11. Rastogi A, Bhadada SK and Bhansali A: An unusual presentation of a usual disorder: Van Wyk-Grumbach syndrome. Indian J Endocrinol Metab 15 (Suppl 2): S141-S143, 2011.

12. Castro-Magaña M, Angulo M, Cañas A, Sharp A and Fuentes B: Hypothalamic-pituitary gonadal axis in boys with primary hypothyroidism and macroorchidism. J Pediatr 112: 397-402, 1988.

13. Omran A, Peng J, Shrestha B, Ashhab MU and Yin F: Male child with Van Wyk-Grumbach's syndrome and other complications of long-standing primary hypothyroidism: A case report. Case Rep Pediatr 2012: 352751, 2012. 
14. Nebesio TD and Eugster EA: Current concepts in normal and abnormal puberty. Curr Probl Pediatr Adolesc Health Care 37: 50-72, 2007.

15. Anasti J, Flack M, Froehlich J, Nelson L and Nisula B: A potential novel mechanism for precocious puberty in juvenile hypothyroidism. J Clin Endocrinol Metab 80: 276-279, 1995.

16. Ryan GL, Feng X, d'Alva CB, Zhang M, Van Voorhis BJ, Pinto EM, Kubias AE, Antonini SR, Latronico AC and Segaloff DL: Evaluating the roles of follicle-stimulating hormone receptor polymorphisms in gonadal hyperstimulation associated with severe juvenile primary hypothyroidism. J Clin Endocrinol Metab 92: 2312-2317, 2007.

17. Kroeze WK, Sheffler DJ and Roth BL: G-protein-coupled receptors at a glance. J Cell Sci 116: 4867-4869, 2003.

18. De Leener A, Montanelli L, Van Durme J, Chae H, Smits G, Vassart $G$ and Costagliola S: Presence and absence of follicle-stimulating hormone receptor mutations provide some insights into spontaneous ovarian hyperstimulation syndrome physiopathology. J Clin Endocrinol Metab 91: 555-562, 2006.

19. Takeuchi K, Deguchi M, Takeshima Y and Maruo T: A case of multiple ovarian cysts in a prepubertal girl with severe hypothyroidism due to autoimmune thyroiditis. Int J Gynecol Cancer 14: 543-545, 2004

20. Rosenfield R, Cooke D and Radovick S: Puberty and its disorders in the female. Pediatr Endocrinol 3: 573-590, 2008.

21. Denef C: Paracrinicity: The story of 30 years of cellular pituitary crosstalk. J Neuroendocrinol 20: 1-70, 2008.

22. Krassas G, Poppe K and Glinoer D: Thyroid function and human reproductive health. Endocr Rev 31: 702-755, 2010.

23. Grattan DR, Jasoni CL, Liu X, Anderson GM and Herbison AE: Prolactin regulation of gonadotropin-releasing hormone neurons to suppress luteinizing hormone secretion in mice. Endocrinology 148: 4344-4351, 2007.
24. Thackray VG, Mellon PL and Coss D: Hormones in synergy: Regulation of the pituitary gonadotropin genes. Mol Cell Endocrinol 314: 192-203, 2010.

25. Francavilla S, Cordeschi G, Properzi G, Di Cicco L, Jannini EA, Palmero S, Fugassa E, Loras B and D'Armiento M: Effect of thyroid hormone on the pre- and post-natal development of the rat testis. J Endocrinol 129: 35-42, 1991.

26. Bruder J, Samuels M, Bremner W, Ridgway E and Wierman M: Hypothyroidism-induced macroorchidism: Use of a gonadotropin-releasing hormone agonist to understand its mechanism and augment adult stature. J Clin Endocrinol Metab 80: 11-16, 1995.

27. Niedziela M and Korman E: Severe hypothyroidism due to autoimmune atrophic thyroiditis-predicted target height and a plausible mechanism for sexual precocity. J Pediatr Endocrinol Metab 14: 901-907, 2001.

28. Silva JE: The thermogenic effect of thyroid hormone and its clinical implications. Ann Intern Med 139: 205-213, 2003.

29. Silveira MG, Mendes FD, Diehl NN, Enders FT and Lindor KD: Thyroid dysfunction in primary biliary cirrhosis, primary sclerosing cholangitis and non-alcoholic fatty liver disease. Liver Int 29: 1094-1100, 2009.

30. Chung GE, Kim D, Kim W, Kim W, Yim JY, Park MJ, Kim YJ, Yoon JH and Lee HS: Non-alcoholic fatty liver disease across the spectrum of hypothyroidism. J Hepatol 57: 150-156, 2012.

31. Chu JY, Monteleone JA, Peden VH, Graviss ER and Vernava AM: Anemia in children and adolescents with hypothyroidism. Clin Pediatr (Phila) 20: 696-699, 1981.

32. Hunold A, Alzen G, Wudy SA, Bluetters-Sawatzki R, Landmann E, Reiter A and Wagner HJ: Ovarian tumor in a 12-year old female with severe hypothyroidism: A case of Van Wyk and Grumbach syndrome. Pediatr Blood Cancer 52: 677-679, 2009. 